\title{
The effect of endophytic colonization of wheat plants by the fungus Beauveria bassiana on the development of the nymphs of the migratory and desert locusts
}

\author{
Maxim Levchenko ${ }^{1}$, Aleksei Gerus ${ }^{1}$, Svetlana Malysh ${ }^{1}$, Saltanat Orazova ${ }^{2}$ and Georgiy \\ Lednev $^{1 *}$ \\ ${ }^{1}$ All-Russian Institute of Plant Protection, Podbelskogo 3, 196608, St. Petersburg, Pushkin, Russia \\ ${ }^{2}$ Kazakh Scientific Research Institute of Plant Protection and Quarantine, Almaty, Republic of \\ Kazakhstan
}

\begin{abstract}
The experiments were aimed at evaluation of the effect of feeding with wheat colonized by the fungus Beauveria bassiana on the development of locusts. The seeds were treated with fungal conidia and 90 days after sowing, the plant parts were fed to II instar nymphs of laboratory colonies of migratory and desert locusts within the period of 18 days. The mortality levels between experimental and control (fed with untreated wheat) groups were not significantly different though a tendency of an increase in variants with contaminated fodder was observed. Two weeks after the beginning of the bioassay, insect mortality was $20-30 \%$ and $15 \%$ in control. As many as $50 \%$ of migratory locust and $40 \%$ of desert locust cadavers were covered by a fungal mycelium. Sequencing of two diagnostic DNA loci has confirmed attribution of the reisolate to the genotype of the initial Beauveria bassiana strain BBK-1. It can be therefore concluded that the endophyte fungus is capable of causing classical pathogenesis of mycosis in locust nymphs. Moreover, the nymphal development was retarded by feeding with the funguscolonized plants.
\end{abstract}

\section{Introduction}

Biological plant protection is largely relied upon the use of microbial formulations [1-3]. It has been shown recently that different entomopathogenic fungi, including representatives of the genus Beauveria may form endophytic associations with plant [4,5]. Numerous works report revealing of these micromycetes in diverse species of wild and cultured plants and confirm the ability of fungi to colonize the plants under experimental conditions. The endophytic fungi are known to negatively affect the insect phytophages and plant pathogens while stimulating the plant growth [6]. Negative impact on the corn borer Ostrinia nubilalis (Lepidoptera: Pyralidae) was found in maize colonized by $B$. bassiana which reduced the number of the pest [7]. Similar observations have been made for certain species of weevils

${ }^{*}$ Corresponding author: georgijled@mail.ru 
(Coleoptera: Curculionidae) and gall wasps (Hymenoptera: Cynipidae) [8, 9]. Similar reports concerning negative effects of entomopathogenic fungi in endophytic form against insects are numerous $[4,5]$. Meanwhile, no such data have been published for Orthoptera, with the exception of one paper [10] where effects of B. bassiana introduced into maize plants as an endophyte onto the host reproduction, feed choice and consumption were traced using Dichroplus maculipennis (Orthoptera: Acrididae: Melanoplinae) as a model. Thus, in spite of being highly promising, research on introduction of entomopathogenic organisms into harmful insect population is limited in case of Acrididae.

In the present paper, we have tested endophyte Beauveria bassiana in winter wheat plants against your instar nymphs of migratory and desert locusts.

\section{Materials and Methods}

The plants were winter wheat Triticum aestuvum, variety "Yuka" grown outdoors using model plots at the experimental station in Krasnodar Territory. The fungal strain used for experiments was $B$. bassiana (BBK-1), cultivated on solid modified Sabouraud medium at $25^{\circ} \mathrm{C}$. Seeds were treated by soaking in water suspension of conidia at concentration of $1 \times 10^{8}$ conidia/mL with addition of $0,1 \%$ Tween- 80 for $20 \mathrm{~h}$. Levels of endophyte colonization were estimated at the phase of 5 true leaves. The plant samples (leaf, stem, root) were sterilized, cut into 5 fragments and placed in Petri dishes onto solid Chapek medium with addition of an antibiotic. Prior to other manipulations, the samples were consequently surface-sterilized with $1 \%$ solution of sodium hypochlorite and $70 \%$ ethanol, followed by triple washing with sterile distilled water. After observation of mycelium growth, fungi were routinely isolated into pure culture and identified using light microscopy and molecular genetic analysis [11]. The model insect hosts were laboratory cultures of migratory locust Locusta migratoria migratorioides and desert locust Shistocerca gregaria from the collection of Moscow Zoo, reared in cages at $32-34^{\circ} \mathrm{C}$ and fed on wheat. Ninety days after sowing the fungal conidia-treated seeds, upper part of plants was used to feed II instar nymphs of both locust species during 18 days. Control insects were fed with untreated plants. Mortality and development rates were scored daily.

\section{Results and Discussion}

The colonization of wheat plants by the fungus $B$. bassiana was successful. The fungus was re-isolated from about $50 \%$ of analyzed plants, showing systemic dispersal over the plant tissues. The roots were the most actively inhabited (50\% of analyzed samples), lesser number of cases $(33 \%)$ was found in stems and the least number - in leaves $(17 \%)$.

No significant differences were found in locust mortality between experimental and control treatments, though in the former case, a tendency of mortality increase was observed (Table 1). After two weeks of the experiment, insect mortality reached 25 до $30 \%$ for migratory and desert locust, respectively, with $15 \%$ mortality of both species in control. When placed into moisture chambers, as many as $50 \%$ and $40 \%$ of cadavers of migratory and desert locust, respectively, were covered with fungal conidiophores, indicating successful infection, characteristic of a classical mycosis. Meanwhile, control insects checked for mycosis were found free from fungal infections. 
Table 1. Mortality of migratory and desert locust nymphs fed with winter wheat grown from seeds treated with Beauveria bassiana

\begin{tabular}{|c|c|c|c|c|c|c|c|}
\hline \multirow{2}{*}{$\begin{array}{c}\text { Locust } \\
\text { species }\end{array}$} & Variant & 5 & 7 & 9 & 11 & 13 & $\begin{array}{c}\text { Rate of } \\
\text { fungal } \\
\text { growth on } \\
\text { cadavers, } \%\end{array}$ \\
\cline { 2 - 8 } & & \multicolumn{7}{|c|}{$\begin{array}{c}\text { Mortality, \% (days) } \\
\text { L. } \\
\text { migratoria }\end{array}$} & B. bassiana & $\begin{array}{c}17,5 \pm 7, \\
0\end{array}$ & $17,5 \pm 7,0$ & $20,0 \pm 8,5$ & $20,0 \pm 8,5$ & $25,0 \pm 8,5$ & 50 \\
\cline { 2 - 8 } & Control & $7,5 \pm 3,7$ & $12,5 \pm 6,5$ & $12,5 \pm 6,5$ & $12,5 \pm 6,5$ & $15,0 \pm 6,3$ & 0 \\
\hline $\begin{array}{c}\text { Sh. } \\
\text { gregaria }\end{array}$ & B. bassiana & $\begin{array}{c}15,0 \pm 5, \\
0\end{array}$ & $22,5 \pm 8,8$ & $27,5 \pm 9,9$ & $30,0 \pm 10,0$ & $30,0 \pm 10,0$ & 40 \\
\cline { 2 - 8 } & Control & $7,5 \pm 3,7$ & $15,0 \pm 6,3$ & $15,0 \pm 6,3$ & $15,0 \pm 6,3$ & $15,0 \pm 6,3$ & 0 \\
\hline
\end{tabular}

Sequencing two diagnostic DNA loci (intergenic spacer Bloc and secreted lipase) confirmed identity of the fungal re-isolates to the B. bassiana BBK-1 genotype. Low level of insect mortality is explained by colonization of only a half of the plants, localization of the fungus mainly in the roots, low infective dosage and its delivery to the insect by oral route (while habitual way of infection is through the teguments).

Another tendency found was retardation of insect development. When insects were fed with the fungus-colonized plants, the proportion of V instar nymphs was 73\% in L. migratoria and $62 \%$ in Sh. gregaria against respective values of 94 and $78 \%$, in control. Conversely, the proportion of III and IV instar nymphs was lower in control (Fig. 1).

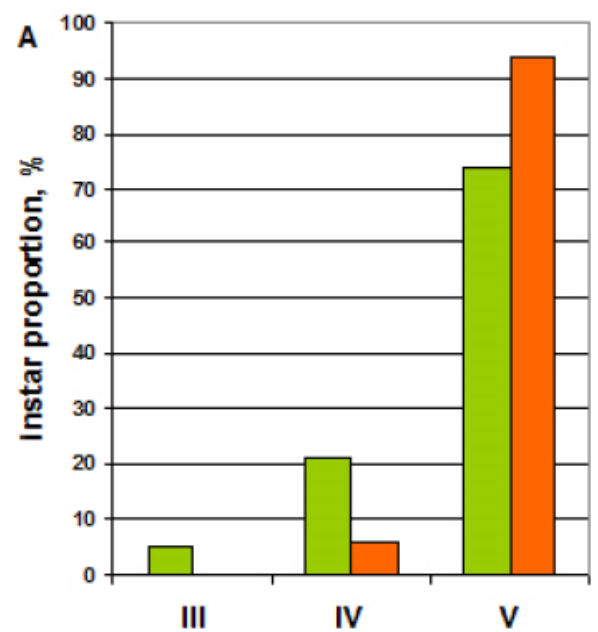

nymph instar

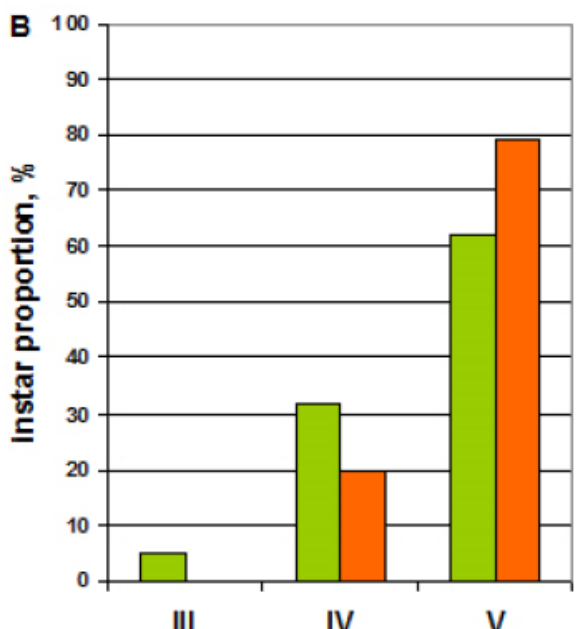

nymph instar

B. bassian a

\section{Control}

Fig. 1. Proportion of migratory (A) and desert locust (B) nymph instars 18 days after feeding with winter wheat grown from seeds treated with Beauveria bassiana 
It can be concluded, that $B$. bassiana BBK-1 is able to colonize wheat plants, infect locusts fed on these plants and retard the development of the phytophages.

The research is supported by Ministry of Education and Science of Kazakhstan Republic, grant \# AP 05135810 .

\section{References}

1. V.A. Pavlyushin, N.A. Vilkova, G.I. Sukhoruchenko, L.I. Nefedova, Plant Protection News [Vestnik zashchity rasteniy] 4(90), 5-18 (2016)

2. G.V. Mitina, E.G. Kozlova, I.M. Pazyuk, Plant Protection News [Vestnik zashchity rasteniy] 2(96), 28-35 (2018) http://doi.org/10.31993/2308-6459-2018-2(96)-28-35

3. L.G. Danilov, Plant Protection News [Vestnik zashchity rasteniy] 3(97), 38-42 (2018) http://doi.org/10.31993/2308-6459-2018-3(97)-38-42

4. Vega F.E. J. Invertebr. Pathol. 98(3), 277-279 (2008)

5. Vega F.E. Mycologia. 110, 4-30 (2018)

6. Ownley B.H., Gwinn K.D., Vega F.E., BioControl. 55(1), 113-128 (2010)

7. Bing, L.A., Lewis, L.C., Environ. Entomol. 20, 1207-1211 (1991)

8. Akello, J., Dubois, T., Coyne, D., Kyamanywa, S., Entomol. Exp. Appl. 129, 157-165 (2008)

9. Quesada-Moraga, E., Muñoz-Ledesma, F., Santiago-Alvarez, C., Environ. Entomol. 38, 723-730 (2009)

10. Pelizza S.A., Mariottini Y., Russo L.M., Vianna M.F., Scorsetti A.C., Lange C.E. J. Insect Sci. 17(2), 1-6 (2017)

11. Lednev G., Tokarev Y., Uspanov A., Malysh J., Duisembekov B., Sabitova M., Levchenko M., Smagulova S., Orazova S., Amanov S., Sagitov A., J. Biotechnol. 185(S), S63-S64 (2014) 